\title{
RETURN STROKES OF TRIGGERED LIGHTNING FLASHES
}

\author{
Minoru Nakano, Nobuyuki Takagi, Zen-ichiro Kawasaki, and Tosio Takeuti \\ Research Institute of Atmospherics, Nagoya University, Toyokawa 442 \\ Kenji Horii \\ Department of Electrical Engineering, Nagoya University, Nagoya 464
}

\begin{abstract}
Return stroke characteistics of the triggered lightning flash are investigated, based on the data of two lightning flashes to a tall chimney and five rocket triggered lightning flashes. These seven lightning flashes were observed within a distance of $1.6 \mathrm{~km}$. A remarkable feature of the triggered lightning is that the lightning flash is composed of more numerous return strokes than the natural lightning flash. The rapid changes within a time of about $10 \mu \mathrm{s}$ is not always found in the luminosity and the electric field change records. The lightning stroke is classified into two types, that is, type A having no rapid changes of the electric field and the luminosity, and type $B$ having the same rapid changes as those in the return stroke of a natural lightning flash. The occurrence frequency distribution of the time intervals between strokes for above two types is different from those of the return strokes and $\mathrm{K}$-changes in the natural lightning flash.

The time intervals of 50 strokes out of 101 are less than 6 ms. The relationship between the characteristics of the return stroke electric field change and the light intensity of the preceeding stroke together with the time intervals, is discussed for the type B strokes.
\end{abstract}

1. Introduction.

In the Hokuriku winter thunderstorms, lightning flashes initiated by upward streamers from a tall tower and a tall chimney are of ten observed (Miyake et al., 1980). A rocket triggered lightning is also initiated by an upward streamer. This type lightning flash is referred to as a 'triggered lightning' in this paper. A lightning ground flash initiated by a downward streamer within the clouds is referred to as a 'natural lightning'. Winter natural ground flash is usually composed of only one or two return strokes. On the other hand, a triggered lightning flash is of ten composed of many return strokes (Hubert and Mouget, 1981, Sumi et al., 1982, Nakano et al., 1983). But the nature of these strokes have not been fully investigated.

The electrical activity of the thunderclouds in which a triggered lightning occurs is about the same as or little lower than the clouds in which a natural lightning occurs. The existence of unusually numerous strokes in a triggered lightning probably indicates the different characteristics of the return strokes and the different breakdown processes from those in a natural lightning. We report preliminary results about the return stroke characteristics, based on the data of the electric field, the magnetic field and the luminosity change due to a triggered lightning flash.

2. Instrumentations and data

The electric field changes due to a lightning flash were recorded by 'slow' and 'fast' antennae. The magnetic field was recorded by a single 
turned loop antenna. An optical system was used to measure leader and return stroke velocities. The reader refers to Nakano et al.(1983) for a complete description about the optical system. All the data were recorded with magnetic tape-recorders which had frequency response extended from $100 \mathrm{~Hz}$ to $1 \mathrm{MHz}$.

Observations were made during the winters of 1981 to 1982 in Hokuriku area, Japan, where active winter thunderstorms of ten develop. In January, 1982, two negative ground flashes composed of multiple strokes to a chimney of $200 \mathrm{~m}$ height were observed at $1 \mathrm{~km}$ distance. In December, 1982, experiments of triggering lightning flash with rocket were made (Horii, 1982). Five rocket-triggered lightning flashes out of seven obserbed at $1.6 \mathrm{~km}$ distance are composed of unusually numerous return strokes. Based on these data, peculiar features of triggered lightning flashes are reported.

\section{Results.}

\subsection{Two types of the stroke.}

Most remarkable feature of a triggered lightning flash is that a flash is composed of unusually numerous return strokes. Fig. 1 shows typical rocket-triggered lightning flash composed of strokes more than 36 .

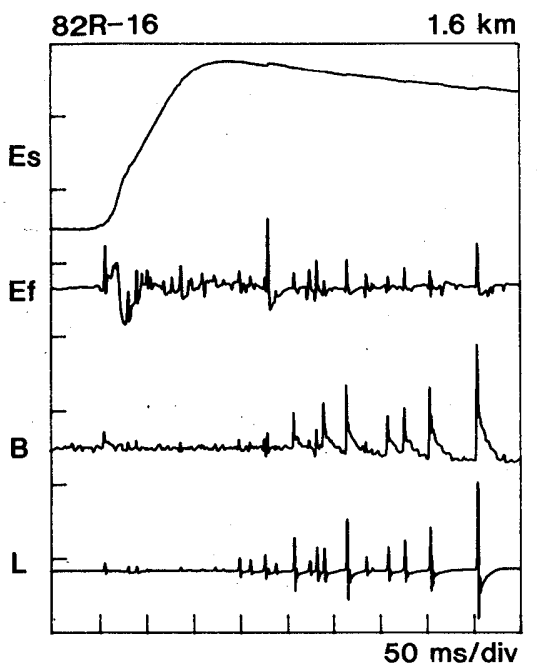

Fig.1. An example of rocket triggered lightning flash at $1.6 \mathrm{~km}$ distance. Es: electric field change by slow antenna, Ef: electric field change by fast antenna, B: magnetic field, and L: 1uminosity change. All data are shown in arbitrary unit.
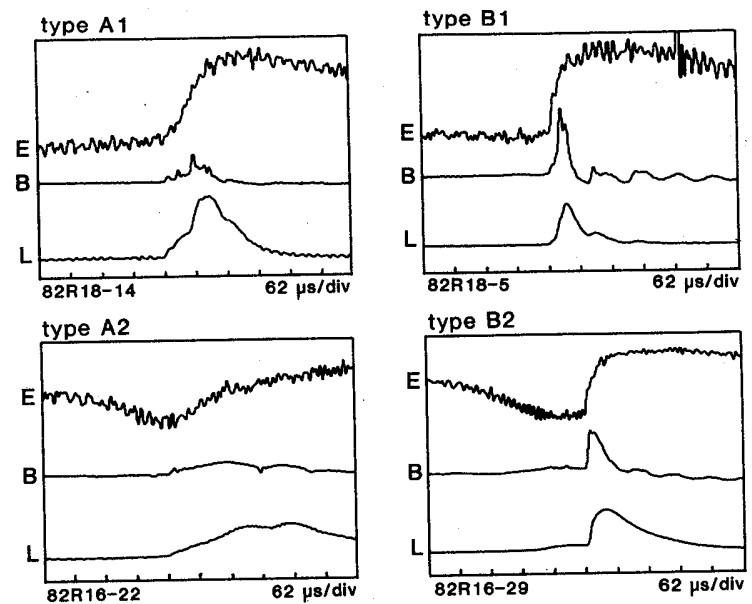

Fig.2. Four types of the electric field, the magnetic field and the luminosity changes. 
The return stroke of a close natural lightning flash consists of very rapid changes of the electric and magnetic fields of a few microseconds and following gradual changes of several tens of microseconds. Thus the return stroke is able to be identified by the electric field change records. On the other hand, the rapid change is not always found in the electric field change records in the triggered lightning flash. We define the discharge component satisfies the following conditions as a lightning stroke : 1) the luminosity change at a certain height below the cloud base and the electric field change are both detected simultaneously, 2) the durations of the luminosity and the electric field changes are both less than approximately $500 \mu \mathrm{s}$, and the rise time of both less than approximately $100 \mu \mathrm{s}$.

The electric field changes are classified into two types. The typical field changes are shown in Fig. 2. While the type A field change shows no rapid change, the type $B$ field change shows rapid change of about $2 \mu$ s to $10 \mu$ sisetime which is the same as that of natural lightning return stroke. Both type field changes are subdivided into $\mathrm{A} 1, \mathrm{~A} 2$ and $\mathrm{B} 1, \mathrm{~B} 2$, respectively. The electric field change of type A2 shows V-shape which is similar to the electric field change of M-components, and the type B2 field change is identical to a leader-return stroke field change in a natural close ground flash. The number of occurrences for each type stroke is given in Table 1.

Table 1. Number of occurrence of each type stroke.

\begin{tabular}{cr}
\hline type & number \\
\hline A1 & 21 \\
A2 & 19 \\
B1 & 5 \\
B2 & 23 \\
misc. & 33 \\
\hline total & 101 \\
\hline
\end{tabular}

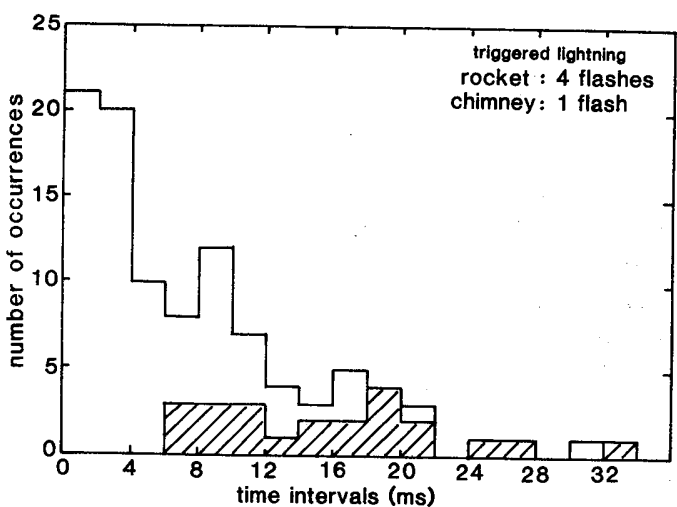

Fig.3. Occurrence frequency of the time intervals between strokes. See text for hatched portions.

\subsection{Time intervals between strokes.}

The occurrence frequency of the time intervals between strokes for 5 flashes including 101 strokes in total is shown in Fig. 3. The occurrence frequency decreases with increasing stroke intervals. The time intervals between strokes in the natural lightning flash is between about $20 \mathrm{~ms}$ and $100 \mathrm{~ms}$ (eg., Schonland, 1956), and the occurrence frequency distribution of $\mathrm{K}$-change intervals shows the maximum at about $4 \mathrm{~ms}$ to $10 \mathrm{~ms}$ (Kitagawa and Brook, 1962). The distribution shown in Fig. 3 is different from those in natural lightning flashes. Hatched portions indicate type B2 strokes in which both downward leader stroke and upward return stroke are definitely confirmed by the luminosity and the electric field change records. The occurrence frequency of these strokes is distributed rather widely but is somewhat shifted into longer time intervals. 
3.3. Rapid electric field change in type B strokes.

As the rapid field change during which the rise time is less than $10 \mu \mathrm{s}$ in the type B stroke corresponds to the breakdown pulse named by Lin et al.(1980), hereafter this rapid change is called as the 'breakdown pulse'. The proportion of the breakdown pulse to total return stroke field change is not constant for each type B stroke. It may primarily depend on the time from a preceeding stroke. Fig. 4 shows the relationship between the ratio, $E b / E r$, of type $B$ field change to the time interval from a preceeding stroke, where $\mathrm{Eb}$ is the electric field change due to breakdown pulse and $\mathrm{Er}$ is the total return stroke field change. Some positive correlation is discernible in Fig. 4. Eb/Er must depend on

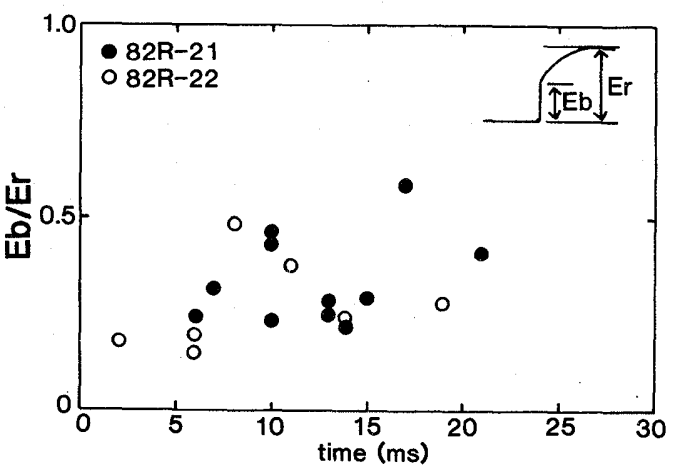

Fig.4. Eb/Er vs. time intervals from a preceeding stroke. The definition of $\mathrm{Eb}$ and $\mathrm{Er}$ is illustrated in upper right in the figure. the electrical properties of the leader channel such as the conductivity, and the net charge distribution which also depend on the grade of ionization, temperature and the pressure of the channel.

We measured the light intensity emitted from the lightning channel section at a certain height with a silicon photodiode having the sensitive range from ultraviolet to infrared. Integrated light intensity corresponds to the radiant energy which should be dependent on the channel temperature, $T$. If the lightning channel is optically thick, the radiant energy is proportional to $\mathrm{T}^{4}$, following Stefan

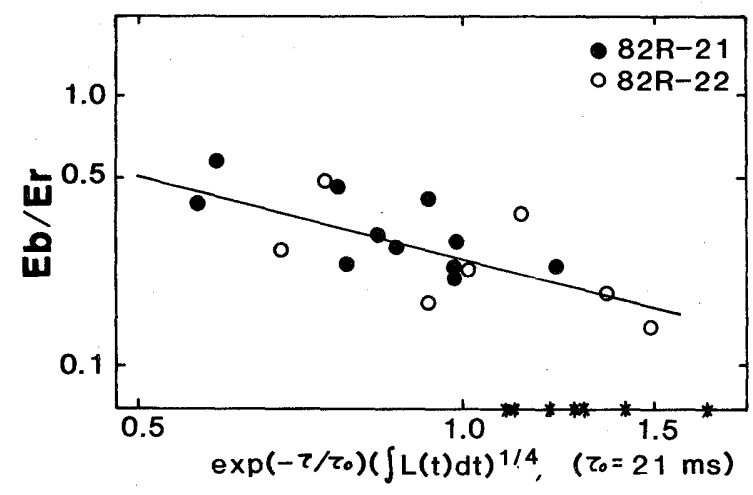
Boltzman's law. Then $T$ is proportional to $\left[\int L(t) d t\right]^{1 / 4}$,

Fig.5. Eb/Er vs. $\exp \left(-\tau / \tau_{0}\right)\left(\int L(t) d t\right)^{1 / 4}$ $\tau$ is the time from the preceeding stroke and $L(t)$ is the light intensity of the preceeding stroke.

where $L(t)$ is the relative light intensity. If the temperature of the return stroke channel decreases exponentially with time, the channel temperature at time $\tau$, after the return stroke is proportional to $\exp \left(-\tau / \tau_{0}\right) T$ i.e. $\exp \left(-\tau / \tau_{0}\right)\left[\int L(t) d t\right]^{1 / 4}$, where $\tau_{0}$ is the decay constant. To evaluate the dependency of Eb/Er on the channel temperature immediately before the return stroke, $\mathrm{Eb} / \mathrm{Er}$ for $\mathrm{n}$ th return stroke is compared to $\exp \left(\tau / \tau_{0}\right)\left[\int L(t) d t\right]^{1 / 4}(=w)$, where $\int L(t) d t$ is taken for $(n-1)$ th stroke and $\tau$ is the time interval between $(n-1)$ th and $n$th strokes. Since $\tau$ and the relative value of $\int L(t) d t$ are determined in the present records, $\mathrm{Eb} / \mathrm{Er}$ vs. $\mathrm{W}$ are plotted as shown in Fig. 5 in a case of $\tau_{0}=21 \mathrm{~ms}$. Here, 
$\tau_{0}$ is chosen so that the correlation coefficient is maximum, which is 0.69 for $\tau_{0}=21 \mathrm{~ms}$. Regression line shown by a solid line indicates that $\mathrm{Eb} / \mathrm{Er}=\mathrm{kW}^{-1.01}$. Under the assumption that $\int \mathrm{L}(\mathrm{t}) \mathrm{dt}$ is proportional to $\mathrm{T}^{4}$, this relation is reduced to $\mathrm{Eb} / \mathrm{Er}=\mathrm{k} / \exp \left(-\tau / \tau_{0}\right) \mathrm{T}$, where $\tau_{0}=21 \mathrm{~ms}$ and $\mathrm{k}$ is constant.

\section{Discussion}

The dart leader was confirmed by the downward propagation of the luminous streamer only for type B2 strokes. For almost all data of two types, later portions of the electric field change was confirmed to correspond to upward propagation of the luminous streamer. It is not clear in the present study whether the upward propagation of the Iuminous streamer in the type A2 stroke corresponds to a return stroke without the rapid change or to a M-component. Only four strokes out of one hundred show downward propagation even in later portion. These rare cases of downward propagation may indicate that similar process to downward propagating M-components observed occasionally by Malan and Collens (1937).

Uman and Voshall (1968) calculated the time and the spatial variations of the channel temperature. They showed that the temperature decreased exponentially with time. From Fig. 4 in their paper, the decay constant can be derived to be about $15 \mathrm{~ms}$ for the channel radius of $1 \mathrm{~cm}$, and about $60 \mathrm{~ms}$ for $8 \mathrm{~cm}$. The decay constant $z_{0}$ of $21 \mathrm{~ms}$ in the present study indicates that the channel radius is between $1 \mathrm{~cm}$ to $2 \mathrm{~cm}$. This is smaller than the diameter of 6 to $7 \mathrm{~cm}$ obtained by recent photographic measurements, but in the range given by several investigators (Orville et al., 1974). It is shown in Fig. 5 that the ratio, $\mathrm{Eb} / \mathrm{Er}$, decreases with increasing $\mathrm{W}$. One might expect the transition from type $B$ to type A occurring in the large value of $\mathrm{W}$. However the data did not show such tendency. The points shown by * in Fig. 5 give the values of $W$ in type $A$ strokes. It is proper that the electrical process corresponding to the breakdown pulse depends not only on the temperature but on the electrical properties of the lightning channel. Since the flashes analyzed were composed of two or three upward branches originated near triggering point, the data of different lightning channel might be treated as those of the same channel. This may be one of the reasons why the data points in Fig. 5 are widely scattered.

We classify the strokes into two types. Type A stroke does not show a breakdown pulse in the electric field change and the luminosity change. The main luminous streamer of type A stroke is confirmed to propagate upward with about the same speed as a return stroke current pulse. Discharge processes of type A strokes remain to be investigated.

Acknoledgement. We wish to thank all the research members and organisations participating in the experiments of triggering lightning with rocket.

\section{References}

Horii, K., Experiment of artificial lightning triggered with rocket, Memoirs of the Faculty of Engineering, Nagoya Univ., 34, 77-112, 1982.

Hubert, P. and G. Mouget, Return stroke velocity measurements in two triggered lightning flash, J. Geophys. Res., 86C, 5253-5261, 1981 .

Kitagawa, N. and M. Brook, A comparison of intracloud and cloud-to-ground lightning discharges, J. Geophys. Res., 65, 1189-1201, 1960.

Lin, L. T., M.A. Uman, and R.B. Standler, Lightning return stroke models, J. 
Geophys. Res., 85C, 15711-1583, 1980.

Malan, D.J., and H. Collens, Progressive lightning 3, Proc. Roy. Soc. Lond. Ser.A, 162, 175-203, 1937.

Miyake, K., S. Yokoyama, H. Mitani, and M. Kumagai, Observations of lightning stroke phenomena in winter season (part 1), Res. Report 181008, Electric Engineering Lab. CRIEPI (in Japanese), 1980.

Nakano, M., T. Takeuti, Z. Kawasaki, and N. Takagi, Leader and return stroke velocity measurements in lightning from a tall chimney, J. Meteor. Soc. of Japan, 61, 339-345, 1983.

Schonland, B.E.J., The lightning discharge, Handbuch der Physik, Springer, New York, 22, 576-628, 1956.

Sumi, S., G. Ikeda, and K. Horii, Lightning current and triggered condition on artificially triggered lightning with rocket at Hokuriku district in winter, Trans. IEE of Japan, 102B, 289-296 (in Japanese), 1982.

(Received November 24, 1983; revised December 16, 1983; accepted December 18, 1983) 